\title{
Prevalence of Anemia and Associated Factors among Children Attended at Jimma Medical Center, South West Ethiopia
}

\author{
Bikila Dereje Fufa, BSc, MSc ${ }^{*}$ and Habtamu Gutema, BSc \\ School of Nursing and Midwifery, Jimma University, Ethiopia
}

*Corresponding author: Bikila Dereje Fufa, BSc, MSc, Lecturer, Faculty of Health Science, School of Nursing and Midwifery, Institute of Health, Jimma University, Jimma, Ethiopia, Tel: +2519-3990-7124

\begin{abstract}
Background: Anemia is major health problem throughout the world. It is associated with serious consequences including growth retardation, impaired motor and cognitive development, and increased morbidity and mortality. Estimates suggest that $47.4 \%$ of children are anemic globally. The magnitude of the problem in developing countries is high, since they are more exposed to various health and socioeconomic problems which are directly or indirectly related with anemia.
\end{abstract}

Objective: To assess the prevalence of anemia and associated factors among Children attended at Jimma Medical Center, South West Ethiopia.

Methods: An institutional based cross-sectional study design was employed from April 15 to 30/2016. Data was collected by face to face interviews by trained data collectors using pretested structured questionnaire. Descriptive statistics was used to analyze the data. Chi-square was used to identify the association between dependent and independent variables with $p$-value $<0.05$.

Result: From the total of 212 children involved in the study, $96(45.3)$ were males and $116(54.7 \%)$ were females with the mean age of the of 6 years. The overall prevalence of anemia was $95(44.8 \%)$ of which $44(20.7 \%)$ males and 51 $(24.1 \%)$ females. The mean hematocrit was $29.3 \%$. From the total observed children $55(26 \%)$ had mild anemia, 31 $(14.6 \%)$ had moderate anemia and $9(4.2 \%)$ had severe anemia.

Conclusion: Generally, the prevalence of anemia has relation with illiteracy of mothers, reduced family income malaria and diarrhea of children, therefore it is better to encourage and practice partners on child health care and to improve it.

\section{Keywords}

Anemia, Children, Ethiopia

\section{Background}

Anemia is a condition in which reduced hematocrit or hemoglobin levels lead to hemoglobin (Hgb) diminished oxygen-carrying capacity that does not optimally meet the metabolic demands of the body, as a result of deficiency of one or more essential nutrients, heavy blood loss, parasitic infections and congenital hemolytic diseases [1]. It is a critical health concern because it affects growth and energy levels adversely. It occurs at all age groups but is more prevalent in pregnant women and children [2]. It damages immune mechanisms and is also associated with increased morbidity [3]. Anemia is a public health problem affecting people in both developed and developing countries with bad consequences of human health as well as social and economic development $[3,4]$. It affects 1.62 billion $(24.8 \%)$ of the population among them it is affecting 305 million (25.4\%) school age children (SAC) [4].

Pediatric anemia refers to a hematocrit level lower than the age-adjusted reference range for healthy children [1]. Anemia creates long term effects among female children resulting in low birth weight babies and postpartum hemorrhage [2,3]. Especially, young children from low income families have a higher risk for developing iron deficiency anemia (IDA) that occurs as a result of high demand for iron during the period of rapid growth, due to this a proper balance of nutrients in this formative period is critical for normal brain development and, shortages of nutrients such as iron and iodine can impair cognitive and motor development [5].

Globally more than a quarter of the world's popula-

Citation: Fufa BD, Gutema H (2019) Prevalence of Anemia and Associated Factors among Children Attended at Jimma Medical Center, South West Ethiopia. Int Arch Nurs Health Care 5:129. doi. org/10.23937/2469-5823/1510129

Accepted: July 13, 2019: Published: July 15, 2019

Copyright: (C) 2019 Fufa BD, et al. This is an open-access article distributed under the terms of the Creative Commons Attribution License, which permits unrestricted use, distribution, and reproduction in any medium, provided the original author and source are credited. 
tion remains anemic and about half of this burden is a result of IDA. The World Health Organization is revising global guidelines for controlling IDA, which stated anemia control programs in developing countries requires careful baseline epidemiologic evaluation, selection of appropriate interventions that suit the population, and ongoing monitoring to ensure safety and effectiveness [6].

In developing countries, the magnitude of the problem is high [7]. The prevalence of anemia among school age children is $40 \%[2,4]$. The problem is alarming in Sub-Saharan African Countries such as Kenya 48.9\% [7], Mali 55.8\% [8] and Tanzania 79.6\% [9]. Lack of awareness among the mothers about the problem coupled with their low educational status, diarrhea can result in loss of nutrients and less to malnutrition, which is highly related with anemia [10]. Dietary factors and socio-demographic factors are the major factors related with high levels of anemia among the children poor nutritional practices and unhealthy food habits [11]; low iron bioavailability of the diet iron seems related to anemia [12].

The magnitude of anemia in Ethiopia by hematological investigation indicated $5.3 \%$ in preschool children, $7.5 \%$ in school age children, $7 \%$ in adult males, and $8.2 \%$ in adult females. Among children of 6.72 months old in urban areas prevalence rate was of $47 \%$ [12].

The study done in Ethiopia among primary school students showed prevalence of anemia was $27.1 \%$, of which $13.8 \%$ had mild, $10.8 \%$ moderate, and $2.3 \%$ severe anemia based on measured $\mathrm{Hgb}$ concentration. Children with in the age group of 5-9 years were at higher risk for anemia. Paternal education was positively associated with anemia. Children who had irregular legume consumption were at higher risk for anemia [13]. Another study done in Ethiopia showed the prevalence of malnutrition in children was 39.2\% [14].

Knowing the magnitude of the problem is helpful in early detection of both moderate and serve anemia to prevent complication. Anemia in children is related with impaired mental and physical development and with increased morbidity and mortality. Anemia can be a particularly serious problem for pregnant women, leading to premature delivery and low birth weight [15]. So, the objective of this study was to assess the prevalence of anemia and associated factors among children in Jimma Medical Center (JMC), South West Ethiopia.

\section{Methods}

\section{Study area and period}

JMC is the largest \& only teaching referral hospital in Jimma Zone \& southwestern part of the country providing services for approximately 15 million people. It has out-patient and inpatient services, maternal and child health services, referral and follow-up services, physio- therapy and rehabilitative services, intensive care and recovery services. JMC is the hospital employed the larger number of nurses at any given time. The hospital has three working shift for nurses, a total of 550 nurses with the total of 500 beds. The study was done from April 15 to $30 / 2016$ G.C.

\section{Study design}

An institutional based cross-sectional study design was employed.

\section{Inclusion and exclusion criteria}

All children visited Jimma medical center during data collection period was included.

\section{Sample size determination}

To determine sample size single population proportion formula was used. Convenience sampling technique was used to include all children visited Jimma medical center during data collection period.

\section{Data collection tools}

Data was collected using pretested structured questionnaire which was interviewed children's family and analyzed using descriptive statistics.

\section{Data collection procedures}

After we examine all children who visited the Jimma JMC Pediatric ward, laboratory investigation of hemoglobin level was conducted for selected children and Child had diarrhea and greater 9 months stool examination was used to assess anemia because in under 9 months children Rota-virus the causes of diarrhea and risk factors intestinal parasite infection.

\section{Data processing and analysis}

Filled data was checked for completeness, cleared and missing value then tallies and scientific calculator were used to analysis manually. Descriptive statistic was computed to summarize the data. Chi-square was used to identify the association between dependent and independent variables at $p$-value $<0.05$.

\section{Ethical consideration}

Prior to data collection ethical approval was given by Jimma University review board then letter of permission was given to JMC. The children's family was informed about the objective and the purpose of the study.

\section{Result}

From the total of 212 children presented to JMC, majority of them 116 (54.7\%) were females. About $25.5 \%$ were in the age group 1-3 years with mean 6 years (Table 1 ).

From the overall prevalence of anemia 95 (44.8\%), $44(20.7 \%)$ males and 51 (24.1\%). The mean hematocrit 
was $29.3 \%$. From the total observed anemic children, 55 (26\%), 31 (14.6\%) and 9 (4.2\%) children had mild, moderate and severe anemia respectively (Table 2$)$.

From the total of children's mothers interviewed, 106 (49.9\%) mothers had no education and 106 (51.1\%) of them can read and write. But only 59 (27.7\%) of children's fathers had no education, and the rest 146 (72.1\%) were literate. 60 (28.3\%) of children whose mothers are illiterate and 29 (13.6\%) whose fathers il-

Table 1: Distribution of children by age and sex.

\begin{tabular}{|l|l|l|l|l|l|}
\hline \multirow{2}{*}{$\begin{array}{l}\text { Age in } \\
\text { Years }\end{array}$} & \multicolumn{4}{|l}{ Sex } & \multicolumn{3}{l|}{ Female } & \multirow{2}{*}{ Total (\%) } \\
\cline { 2 - 5 } & Male & \multicolumn{3}{|l|}{} \\
\cline { 2 - 5 } & No & $\%$ & No & $\%$ & \\
\hline$<1$ & 22 & 10.4 & 27 & 12.7 & 23.1 \\
\hline $1-3$ & 27 & 12.7 & 32 & 15.1 & 27.8 \\
\hline $3-6$ & 28 & 13.2 & 31 & 14.6 & 27.8 \\
\hline $6-12$ & 19 & 9 & 26 & 12.3 & 21.3 \\
\hline Total & 96 & 45.3 & 116 & 54.7 & 100 \\
\hline
\end{tabular}

literate were anemic. From the total study children, stool examination was done for 119 children of which $25(11.7 \%)$ and $23(10.8 \%)$ had hookworm and Ascaris respectively. But 17 (8\%) children had both hook worm and anemia. From the total children, 98 (46.2\%) had diarrhea from which 64 (30.2\%) were anemic. From the total children investigated, 159 (75\%) of them had no history of malaria of which 81 (38.2\%) were anemic (Table 3).

\section{Factors associated with anemia among children}

There was significant association between malaria and anemia $\left(x^{2}=9.67, p=0.001\right)$. There was association between diarrhea and anemia $\left(x^{2}=30.95, p=\right.$ $0.000)$. Anemia had significant association with mother illiterate $\left(x^{2}=11.920, p=0.000\right)$ but statistically. Family income had significant association with anemia $\left(x^{2}=\right.$ $47.014, p=0.000)$, but there was no significant association with sex and age of child $\left(x^{2}=11.925, p=0.992\right)$, respectively (Table 3 ).

Table 2: Distribution of anemia by age and sex, among children.

\begin{tabular}{|l|l|l|l|l|l|}
\hline \multirow{2}{*}{$\begin{array}{l}\text { Age in } \\
\text { Years }\end{array}$} & \multicolumn{3}{|l|}{ Sex } & Female & Total (\%) \\
\cline { 2 - 6 } & Male & No (\%) & Yes (\%) & No (\%) & \\
\cline { 2 - 6 } & Yes (\%) & $13(6.1)$ & $12(5.7)$ & $15(7.0)$ & $49(23)$ \\
\hline$<1$ & $9(4.2)$ & $16(7.6)$ & $14(6.7)$ & $17(8.0)$ & $59(28)$ \\
\hline $1-3$ & $12(5.7)$ & $14(6.7)$ & $15(7.0)$ & $16(7.6)$ & $55(26)$ \\
\hline $6-6$ & $10(4.7)$ & $11(5.2)$ & $10(4.7)$ & $15(7.0)$ & $49(23)$ \\
\hline Total & $13(6.1)$ & $54(25.6)$ & $51(24.1)$ & $63(29.6)$ & $212(100)$ \\
\hline
\end{tabular}

Table 3: Association of anemia with other risk factors among children.

\begin{tabular}{|c|c|c|c|c|c|}
\hline \multirow[t]{2}{*}{ Variables } & \multirow[t]{2}{*}{ Category } & \multicolumn{2}{|l|}{ Anemia } & \multirow[t]{2}{*}{ Chi-square } & \multirow[t]{2}{*}{ P-value } \\
\hline & & Yes & No & & \\
\hline \multirow[t]{2}{*}{ Sex } & Male & $44(24.1)$ & $54(25.6)$ & \multirow[t]{2}{*}{0.0006} & \multirow[t]{2}{*}{0.9812} \\
\hline & Female & $51(24.1)$ & $63(29.6)$ & & \\
\hline \multirow[t]{4}{*}{ Age } & $<1$ & $21(9.9)$ & $28(13.1)$ & \multirow[t]{4}{*}{0.187} & \multirow[t]{4}{*}{0.979} \\
\hline & $1-3$ & $26(12.4)$ & $33(15.6)$ & & \\
\hline & $3-6$ & $25(11.7)$ & $30(14.3)$ & & \\
\hline & 6-12 & $23(10.8)$ & $26(12.2)$ & & \\
\hline \multirow{2}{*}{$\begin{array}{l}\text { Educational status of } \\
\text { mothers }\end{array}$} & Illiterate & $60(28.3)$ & $46(21.6)$ & \multirow[t]{2}{*}{11.92} & \multirow[t]{2}{*}{0.00055} \\
\hline & Literate & $35(16.5)$ & $71(33.4)$ & & \\
\hline \multirow[t]{2}{*}{ Educational status of fathers } & Illiterate & $29(13.6)$ & $30(14.1)$ & \multirow[t]{2}{*}{0.363} & \multirow[t]{2}{*}{0.546} \\
\hline & Literate & $65(30.6)$ & $81(41.5)$ & & \\
\hline \multirow[t]{2}{*}{ Malaria } & Positive & $14(6.6)$ & $39(18.4)$ & \multirow[t]{2}{*}{9.67} & \multirow[t]{2}{*}{0.0018} \\
\hline & Negative & $81(38.2)$ & $78(36.8)$ & & \\
\hline \multirow[t]{2}{*}{ Diarrhea } & Yes & $64(30.2)$ & $34(16.0)$ & \multirow[t]{2}{*}{30.95} & \multirow[t]{2}{*}{0.00001} \\
\hline & No & 31 (14.6) & $83(39.2)$ & & \\
\hline \multirow{4}{*}{$\begin{array}{l}\text { Income in dollars } \\
27 \mathrm{ETB}=1 \mathrm{USD}\end{array}$} & $\leq 55$ & $58(27.3)$ & $28(13.2)$ & \multirow[t]{4}{*}{30.95} & \multirow[t]{4}{*}{0.00001} \\
\hline & $55-225$ & $29(13.6)$ & $22(10.3)$ & & \\
\hline & $225-700$ & $9(4.2)$ & $30(14.2)$ & & \\
\hline & $>700$ & $3(1.4)$ & $33(15.5)$ & & \\
\hline
\end{tabular}




\section{Discussion}

The overall prevalence of anemia obtained in this study was (44.8\%). Out of the study subjects, $(20.7 \%)$ males and $(24.1 \%)$ females were anemic. The prevalence of anemia between male and female was no statistically significant association with anemia. This might be because male and female children were equally exposed to predisposing factors of anemia unlike that of adult male and female. Females are more susceptible to develop anemia because of blood lose during menstruation and labor.

The prevalence obtained $(44.8 \%)$ is higher than the prevalence of anemia was $39.1 \%$ as it was done in Asendabo Town, South West of Ethiopia [16]. The prevalence obtained in this study is lower compared to study obtained in health facility in rural Nigeria (68\%) [17]. This variation of prevalence of anemia could be due to geographical variation, socioeconomic status, variation in method of determination and sample size.

Severe anemia was detected among 4.2\% which is less than severe anemia detected in Agaro Health Center 8\% [18], but higher from study done in Somali region South East Ethiopia 1.9\% [19]. Anemic children were grouped by age and those children between the age group 1-3 years were the most affected ones. This might be attributable to lack of fulfillment for increased requirement of necessary nutrients for hemoglobin synthesis in these age groups especially at the age of two years $[16,17]$.

Anemia can be associated with multiple predisposing factors like malaria, diarrhea, educational status and income. Malaria infection causes lyses of red cells and cause anemia. According to the result of this study there was statistically significant association between history of malaria infection and anemia. The result of this study showed, $25 \%$ had history of infection with malaria in the last year of which $4.6 \%$ of children were anemic, higher than malaria infected children study done hospital-based in southern Papua, with $12 \%$ of all severe anemia at the hospital attributable to $P$. vivax, $P$. malariae, or mixed species infections [20].

Children with history of diarrhea before two weeks of the study more likely to be anemic than, children without diarrhea. Diarrhea can lead to loss of nutrients and may lead to malnutrition which can cause anemia [10]. Also, in this study diarrhea has statistically significant association with anemia.

Educational status of the family is one of the factors which can be considered as a risk factor of anemia in children if children's family especially in this study, mother's educational level were found to be important determinants of anemia. Mothers' level of education may positively influence practices related to the health care and feeding practice of their children mothers are illiterate and not aware how to supply important nutrients their children can develop anemia. Anemia was statistically significant association with mother illiterate, but statistically no significant association with father illiterate.

In this study, anemia among children was also associated with house income. Children living in house hold lower monthly income was more likely to have anemia compared those higher income. This is due to the reason that children from poor households are less likely to get iron-rich foods like animal foods and vitamin-rich foods especially vitamins $A$ and $C$ which are very important for iron absorption. Out of 36 who had $>18900$ birr/ month family income only $3(1.4 \%)$ were anemic as from 86 who had $<1500 \mathrm{birr} /$ month family monthly income $58(27.3 \%)$ were anemic, but lower than study done in Jimma town South West Ethiopia per the monthly income of the families, the prevalence of anemia among children who belonged to families' earning an average monthly income of less than 500 ETB was 64.1\% [15].

\section{Limitation of study}

The study lacks detailed investigation of the morphological appearance of red blood cells to differentiate anemia due to vitamin $B_{12}$ and folic acid deficiencies from anemia due to iron deficiency.

Other limitation is selection bias because children come to the hospital were sick and had higher chance of being anemic than children in the community.

\section{Problem encountered}

Shortage of reference material to compare with similar studies at the same area. Shortage of time was one of the problems encountered.

\section{Conclusion}

In general, the prevalence of anemia among children visiting Jimma University specialized hospital in Jimma Town was high $44.8 \%$. This study also showed that mild and moderate levels of anemia were found to be $26 \%$ and $14.6 \%$ respectively, while only $4.2 \%$ of severe anemia observed in the present study. It was established that occurrence of anemia is directly related with parents' income and maternal literacy status, malaria and diarrhea of children. Therefore, poverty alleviation and improving the economic status of the society is a crucial strategy to reduce the prevalence of anemia. General adult education to parents and health education to the community are also important strategies to reduce the burden of anemia.

\section{Author Contributions}

BD involved substantial contributions to conception and design of the study, data collection, and data analysis, interpretation of data and drafting and critically reviewing the manuscript. Likewise, HG involved in designing of the study, analysis of the data and critically reviewing the manuscript. All authors read and approved the final manuscript. 


\section{Conflicts of Interest}

There are no conflicts of interest.

\section{Acknowledgement}

First and for most we would like to thank our Almighty God for His help in all walk of our life and for giving us healthy and great help during day and night time to do this study. And also, our great thanks go to all participants of the study for their willingness, genuine information and the time sacrifices.

\section{References}

1. Susumu Inoue, Robert J Arceci (2013) Pediatric acute anemia.

2. United Nations Children's Fund, United Nations University, WHO (2001) Iron deficiency anemia. Assessment, prevention and control - A guide for programme managers. World Health Organization, Geneva, 15-31.

3. WHO (2002) The World Health Report 2002: Reducing risks, promoting healthy life. World Health Organization, Geneva, 49-93.

4. Benoist B, McLean E, Egli I, Cogswell M (2008) Worldwide prevalence of anemia 1993-2005: WHO Global Database on Anemia. World Health Organization, Geneva, 7-13.

5. Marc Goodman-Bryan (2011) The role of nutrition in brain development.

6. Pasricha SR, Drakesmith H, Black J, Hipgrave D, Biggs BA (2013) Control of iron deficiency anemia in low- and middleincome countries Blood 121: 2607-2617.

7. Neumann CG, Bwibo NO, Murphy SP, Sigman M, Whaley $S$, et al. (2003) Animal source foods improve dietary quality, micronutrient status, growth and cognitive function in Kenyan school children: Background, study design and baseline findings. J Nutr 133: 3941-3949.

8. Hall A, Roschnik N, Ouattara F, Touré I, Maiga F, et al. (2002) A randomised trial in Mali of the effectiveness of weekly iron supplements given by teachers on the haemoglobin concentrations of school children. Public Health Nutr 5: 413-418.

9. Tatala SR, Kihamia CM, Kyungu LH, Svanberg U (2008) Risk factors for anemia in school children in Tanga Region, Tanzania. Tanzan J Health Res 10: 189-202.
10. Alaofè H, Zee J, Dossa R, O’Brien HT (2009) Education and improved iron intakes for treatment of mild iron-deficiency anemia in adolescent girls in southern Benin. Food Nutr Bull 30: 24-36.

11. Kikafunda JK, Lukwago FB, Turyashemererwa F (2009) Anemia and associated factors among under-fives and their mothers in Bushenyi district, Western Uganda. Public Health Nutr 12: 2302-2308.

12. Hashizume M, Shimoda T, Sasaki S, Kunii O, Caypil W, et al. (2004) Anemia in relation to low bioavailability of dietary iron among school-aged children in the Aral Sea region, Kazakhstan. Int J Food Sci Nutr 55: 37-43.

13. Firehiwot Mesfin, Yemane Berhane, Alemayehu Worku (2015) Anemia among primary school children in Eastern Ethiopia. PLoS ONE 10: e0123615.

14. Djokic D, Drakulovic MB, Radojicic Z, Crncevic Radovic L, Rakic L, et al. (2010) Risk factors associated with anemia among Serbian school-age children 7-14 years old: Results of the first national health survey. Hippokratia 14: 252-260.

15. Central Statistical Agency [Ethiopia], ICF International (2012) Ethiopia Demographic and Health Survey 2011. Addis Ababa, Ethiopia and Calverton, Maryland, USA, 173176.

16. Selomon Assefa, Andualem Mossie, Leja Hamza (2014) Prevalence and severity of anemia among school children in Jimma Town, Southwest Ethiopia. BMC Hematol 14: 3.

17. Joycelye E Ewusie, Clement Ahiadeke, Joseph Beyene, Jemila S Hamid (2014) Prevalence of anemia among under-5 children in the Ghanaian population: Estimates from the Ghana demographic and health survey. BMC Public Health 14: 626.

18. Pauloy $R$ (2014) Prevalence of anemia in under 5 children in Agaro health center. JIHS Professor of Pediatrics, New York Medical College.

19. Bekele Gutema, Wondimagegn Adissu, Yaregal Asress, Lealem Gedefaw (2014) Anemia and associated factors among school-age children in Filtu Town, Somali region, Southeast Ethiopia. BMC Hematol 14: 13.

20. Nicholas M Douglas, Daniel A Lampah, Enny Kenangalem, Julie A Simpson, Jeanne R Poespoprodjo, et al. (2013) Major burden of severe anemia from non-falciparum malaria species in Southern Papua: A hospital-based surveillance study. PLoS Med 10: e1001575. 